\title{
Think about the joints
}

\author{
ET Mosley ${ }^{1 *}$, AM McMahon ${ }^{1,2}$ \\ From 18th Pediatric Rheumatology European Society (PReS) Congress \\ Bruges, Belgium. 14-18 September 2011
}

\section{Background}

Musculoskeletal problems are common in children. The majority are self-limiting and related to trauma; however the symptoms can be feature of serious medical conditions.

It has been previously shown that musculoskeletal examination is poorly documented. Musculoskeletal examination is a station on the $\mathrm{RCPCH}$ clinical exam. Teaching resources on how to perform musculoskeletal examinations are freely available together with guidelines on when musculoskeletal examination should be performed.

\section{Aim}

Recent research has shown that such examinations are highly acceptable to parents and patients; therefore we aimed to see if the situation has improved.

\section{Method}

Random selections of patients attending the assessment unit at a large tertiary children hospital in a 1-week period were reviewed. The inclusion of a musculoskeletal examination was reviewed.

Standard used for inclusion of musculoskeletal examination:

- Child with muscle joint or limb pain

- Unwell child with pyrexia

- Limping child

- Delay of milestone

- Clumsy child in the absence of neurological signs

- Associated conditions/chronic diseases e.g. inflammatory bowel, cystic fibrosis, arthritis, psoriasis

Red Flags (concern about infection, malignancy or NAI)

- Fever, malaise

- Bone/joint pain
Table

\begin{tabular}{ll}
\hline Trigger & Number \\
\hline Fever & 17 \\
Limp/joint pain & 1 \\
Red flag (excluding fever) & 2 \\
\hline
\end{tabular}

- Refractory pain, persistent night sweats

- In congruency between history and presentations

\section{Results}

20 admissions, totalling 49 patients were reviewed.

20 patients had presenting symptoms to advocate the inclusion of musculoskeletal examinations

Only 2 patients had documented musculoskeletal examinations.

\section{Conclusions}

Despite the availability of educational training resources there has been little improvement in the inclusion of this musculoskeletal examination in clinical practice.

Whilst this was a small sample it highlights the need for further education at all levels in when and how to perform a musculoskeletal examination.

\section{Author details}

'Sheffield Children's Hospital, Sheffield, UK. '2Leeds Children's Hospital, Leeds, UK.

Published: 14 September 2011

doi:10.1186/1546-0096-9-S1-P116

Cite this article as: Mosley and McMahon: Think about the joints.

Pediatric Rheumatology 2011 9(Suppl 1):P116.

\footnotetext{
* Correspondence: ellen.mosley@sch.nhs.uk

'Sheffield Children's Hospital, Sheffield, UK

Full list of author information is available at the end of the article
}

(c) 2011 Mosley and McMahon; licensee BioMed Central Ltd. This is an open access article distributed under the terms of the Creative 